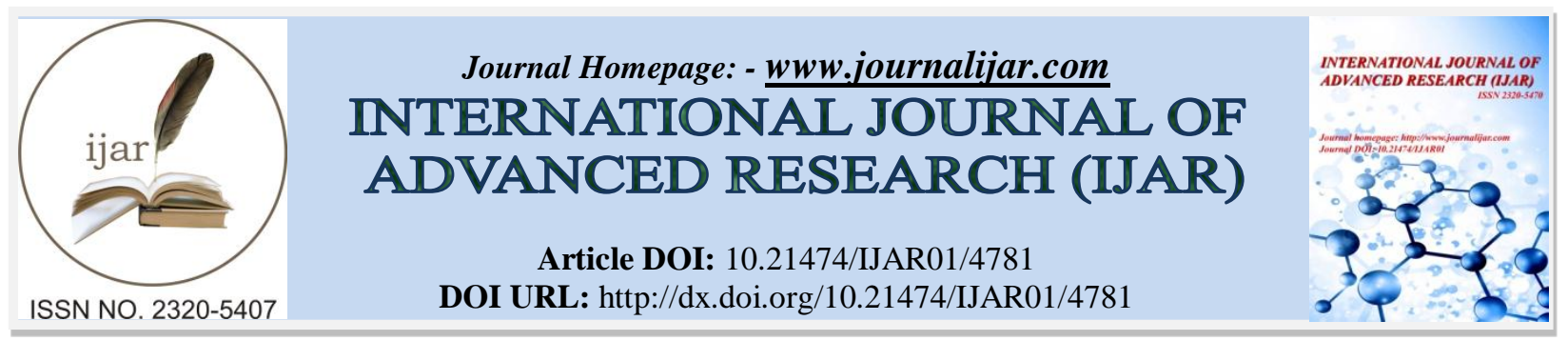

RESEARCH ARTICLE

\title{
SAFETY SERVICES: A GLOBAL INDEX PROPOSAL FOR INNOCUOUSNESS MANAGEMENT IN RESTAURANTS.
}

\author{
Yadrian Arnaldo Garcia Pulido ${ }^{1}$, Alberto Arnaldo Medina Leon ${ }^{2}$, Roberto Argelio Frias Jimenez ${ }^{2}$ and \\ Rebeca Milenys Jaquinet Espinosa ${ }^{2}$ and Leonardo Manuel Cuetara Sanchez ${ }^{3}$. \\ 1. Matanza's University, Cuba. Quality Department. \\ 2. Matanza's University, Cuba. International relations. \\ 3. Equinoctial Technologic University, Quito, Ecuador. Tourism Observatory Department.
}

\section{Manuscript Info}

\section{Manuscript History}

Received: 8 May 2017

Final Accepted: 10 June 2017

Published: July 2017

Key words:-

Innocuousness, hygienic prerequisites, HACCP, food safety

\section{Abstract}

The knowledge of food safety and innocuousness is indispensable when it is referred to foods and drinks production. For its management, it is required a previous guarantee of hygienic requirements fulfilment. This subject constituted the objective of this research, whose purpose was the proposal of an instrument to evaluate the hygienic prerequisites in gastronomic services. The index proposed was validated in a study object. The instrument was based on the importance of selected criteria's and its fulfilment according to a checklist. This first analysis it is complemented with a calculation base which contribute to the quantitative character of the method. The proposed instrument shows up automated for a better application. Like main results were obtained an Index proposal of hygienic prerequisites fulfilment (IGHSm), a manual drives for the application of the IGHSm and the proposal of 11 improving actions for the innocuousness management in the study object.

Copy Right, IJAR, 2017,. All rights reserved.

\section{Introduction:-}

Everybody have the right to a nutrition made suitable, to the outburst to foods that are good quality, innocuous and nutritious. That's why, it is necessary to guarantee the maximum protection of the consumers, that is to say the innocuousness of the products in the course of the whole food chain, from production to consumption, by the integration of manufacturers, carriers, distributors, salespeople and consumers. Then, the changes in the patterns of consumption, not only demand bigger guarantees of innocuousness, but also quality in the products (Carballo, Villarreal \& del Toro, 2012).

According to Todt (2008) is necessary to look for a new international consent on the alimentary system that comprises not only the issues of health but also of the issues derived of the people that as the consumers appreciate the quality of the foods and like society they worry about side effects (ethics, biodiversity, sustainability, etc.).

The alimentary crises that happen in the world in recent times and the fact that nutrition is a primary and fundamental need of the man, evidence the importance that measures that guarantee the food merchandising are applicable innocuous with the aim of preserving the people health (Espinosa et al., 2010). 
The incidence of foodborne diseases, are an aspect very debated, few of they are reported (between the 1 and $10 \%$ of the cases) and still less investigated. Between the causes of its increase are: the increase of the international tourism, the increment of the international trade of foods, modifications in the feeding habits of the population, bigger number of individuals' immune engaged and the appearing of emerging pathogens transmitted by the foods (Suárez, 2012).

These diseases afflict principally the poorest and fragile sectors of the population, so much that a lot of countries have gotten to consider eat one of the bigger public national health problems inclusively certain organizations consider that this is a worldwide big problem (Armendáriz, Monge \& Zhunio, 2012).

The theme of food safety and health has always been priority for the travellers since in the case of getting sick in the course of the displacement or already when are in destination, it is practically the end of an unforgettable experience that was searching (Boletín turístico 5130, 2014). The food safety can be understood like the availability of foods or innocuous foods, in this investigation were assumed the related with innocuous foods itself, due to its repercussion in consumer health, if we has present that it's not guarantee can be cause disease to the customer.

The World Health Organization put forward that over $70 \%$ of the cases of foodborne diseases (ETAs) are originate due to an unsuitable manipulation. Factors like the quality of the raw material, the ambient conditions, the characteristics of the equipment's used in preparation and the technical hygiene conditions are important points in the foodborne diseases epidemiology (Correia, 2012). In order to avoid the ETAs the guarantee of innocuousness is necessary, with regard to this matter in Cuba the State-Owned Health Inspection (ISE), and is the forewoman of the fulfilment of the same. About the end of 2014 an ISE in the gastronomic services associated to a touristic destination had total success where were evaluated 57 indicators classified in: of Management, of Investment and Constructive. Getting along well the ones of management those related with manipulation, the management properly and processes, besides feasible to improve in a short period of time. The ones of investment are refer to those aspects whose solution implies purchase of raw materials, produces and or materials, importance repairs and whose solution can require a period of bigger time in some cases. The constructive ones finally are related to the infrastructure of the facilities or that their improvement entails building works. The results of the non-fulfilment by indicator type give the appearance of being in the following figure where the deficiency that exists in the tourist destination of Varadero's becomes evident (García, 2014).

Percentage non-fulfillment indicators by type

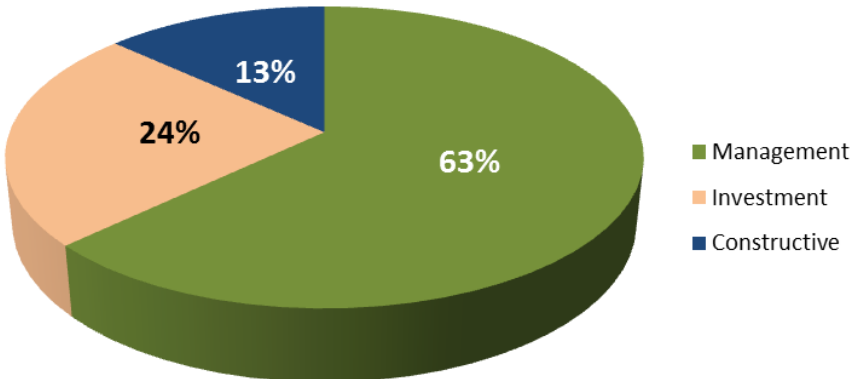

Figure 1:- Non-fulfilment indicators percentage by type in 30 hotels gastronomic services on Varadero's destination.

Source: taken from (García, 2014)

The above evidences that the present-day situation of the hotel industry presents still deficiencies regarding the innocuousness management. The same one can be negotiated from the tool HACCP that is born according to Barrio (2009), with the firm objective to unroll mechanisms that will provide a tall level of guarantees on the food safety.

In order to treat the related thing with the discussed themes there are a set of standards of national and international character between them they find in the international blueprint the IFS (International Food Standard) that has like basic objectives a) establishing a common standard with a system of uniform evaluation, b) working with the credited and well-qualified certification bodies and authorized auditors; c) guaranteeing the transparency in the whole chain of supply, and d) reducing costs and time as much for the suppliers and retailers. And the ISO 
22000:2005 that defines the requirements for a management system once the innocuousness was referred of the foods and cover up all the types of organizations, from the farmers to supply, once the packing was included.

This standard specifies the requirements for an innocuousness management system for foods that combines the key elements generally recognized, to assure the foods innocuousness in the course of the whole food chain, to the extent of final consumption (García \& Cepero, 2014).

In the national blueprint the NC 136:2017 establishes the principles of HACCP system and the guiding principles for its practical application. The NC 143:2007 is applicable like useful list of verification of the requirements for the authorities. The NC 453:2006 of character obligatory, establishes the sanitary general requirements that the establishments and other facilities dedicated to the collective nutrition will do their job, as well as, for the foods that in them become elaborate and or they consume. And the NC 455:2006 of obligatory character equally, establishes the sanitary requirements that the manipulators and any other staff in similar activities will do their job; in the operations of food manipulation during its obtaining, elaboration, processing, bottled, reception, storage, transportation and sale.

However Villalobos and collaborators (2010) refer a series of barriers that limit the HACCP system implantation, namely: a) insufficiencies in the hygienic culture of the manipulators, b) resistance and lack of motivation to confront the necessary changes, c) infrastructure unsuitable with lack of control instruments, d) insufficient technical conditions for the fastening of hygiene and weaknesses in the programs of cleanliness and disinfection, e) nonfulfilment of the Forward Line Principle and f) insufficient training of manipulators, executives and or managers once them were entailed on.

Furthermore, the effectiveness of system implantation depends upon the fulfilment of a series of hygienic prerequisites, where the companies that guarantee the same had 9.7 time more possibilities of implanting the HACCP system (Celaya, 2004).

In addition López \& Osorio (2012) and Moya \& Zubieta (2013), recognize that the realization of a diagnosis of the hygienic conditions is vital, previous to the HACCP system implementation. In concordance (Suárez, et al., 2007; Avila, 2010 and Macías, 2013) put forward that it's fulfilment proves to be indispensable for the innocuousness guarantee.

\section{Methods and Procedure:-}

A total of 13 methodologies were analysed for the prerequisites diagnosis where it took place to the conclusion that tools are insufficient employed. Because the scales of measurement proposed do not correspond themselves with the true intentions when it is a matter of food safety, besides the majority, with the exception of the IGHS, does not propose a level of importance between the indicators, as well as the no establishment of a minimal limit out of courtesy (García \& Cepero, 2014). The tool more accepted is the IGHS, which is why constituted the base, next to the EVALROC for the present proposal.

The instrument proposes 10 indicators, with a total of 116 criteria of measure, of these, 10 invalidates whose fulfilment is binding. The indicators selected for the tool correspond with the proposed in the IGHS, for in mail with (García \& Cepero, 2014) these indicators form important part at the time of analysing innocuousness, besides are present at the national standards before commented. There are:

Table 1:- Selected indicators.

\begin{tabular}{|c|c|c|c|}
\hline Number & Indicator & Number & Indicator \\
\hline I & Human resources & VI & Infrastructure \\
\hline II & Dry storage & VII & Food's supply \\
\hline III & Cold storage & VIII & Solids and liquids wastes management \\
\hline IV & Vector control & IX & Maintenance of equipment's, sites and facilities \\
\hline V & Cleanliness and disinfection & $\mathbf{X}$ & .
\end{tabular}

Source: taken from García y Cepero (2014). 
One of the advantages consists in the granting from weights -an importance level- to the indicators, the IGHSm is calculated from the value once the weights were granted of every indicator. This pondering given, indicate a value of importance to each indicator because they all do not cause the same impact level.

Table 2:- Pondering values for each indicator.

\begin{tabular}{|c|l|c|l|}
\hline IndicaTor & W & IndicaTor & W \\
\hline I & 0.094 & VI & 0.056 \\
\hline II & 0.090 & VII & 0.141 \\
\hline III & 0.119 & VIII & 0.111 \\
\hline IV & 0.106 & IX & 0.078 \\
\hline V & 0.129 & X & 0.071 \\
\hline
\end{tabular}

Table 3:- Criteria of measures values in order its fulfilment.

\begin{tabular}{|c|c|}
\hline ValUE & MEANING \\
\hline+1 & Criteria fulfilment \\
\hline-1 & Criteria fulfilment \\
\hline
\end{tabular}

The instrument uses a dichotomy scale (Table 3). For the indicators evaluation a checklist that contains the 116 criteria of measure was designed. All the answers suggested themselves like: Fulfilment criteria (Yes)/Nonfulfilment criteria (No). At this way if the answer is positive then grant value $(+1)$, but if it's negative $(-1)$.

The theoretic conception of the global index was based on the EVALPROC method proposed by (Frías, et al., 2008).

Figure 2:- Theoretical conception of global index prerequisites fulfilment.

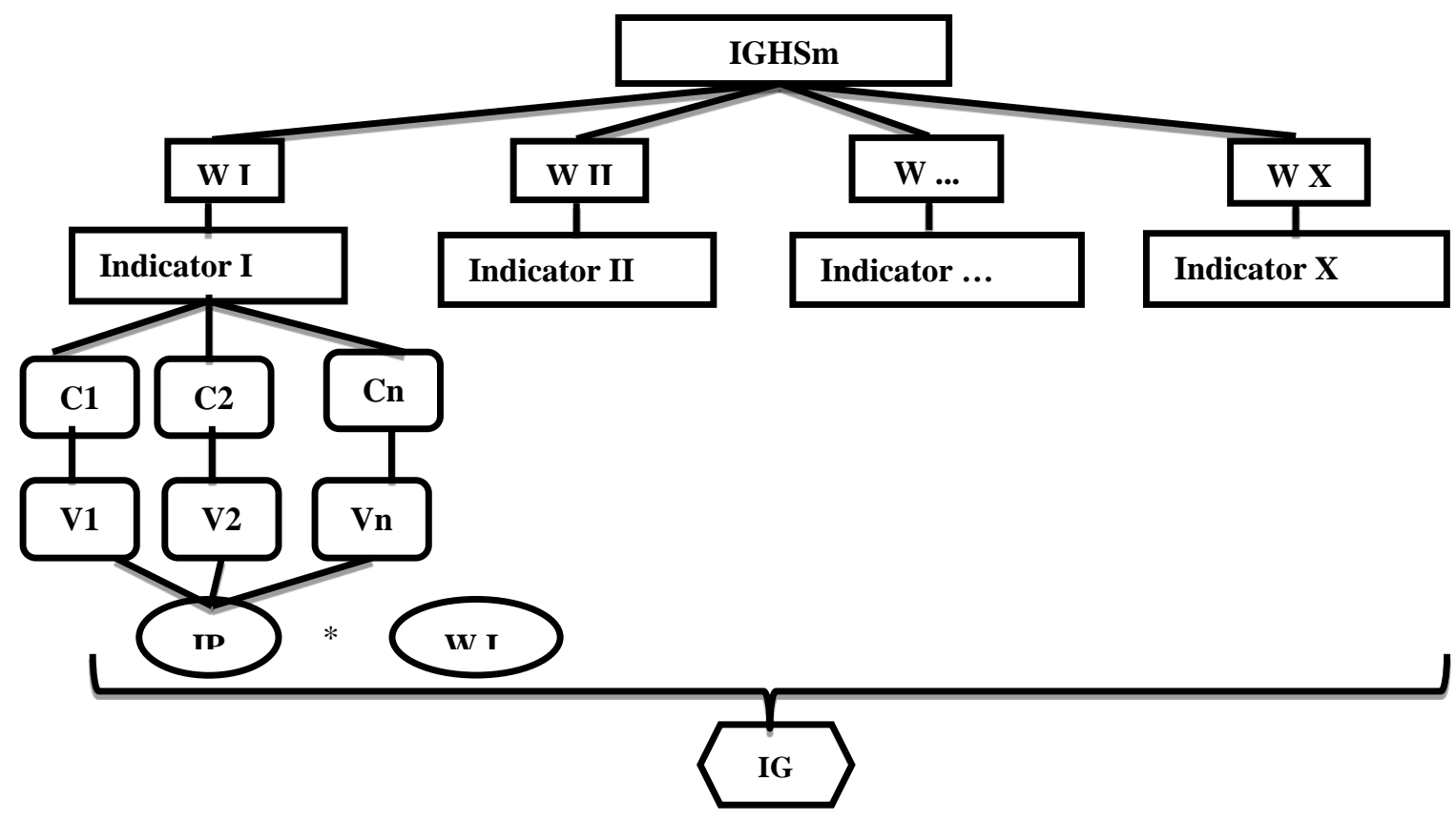

These values constituted the base of calculation for Global index fulfilment prerequisites determination for the HACCP system implantation (IGHS modified), where:

$$
I G H S m=\sum I p n * W n \quad I p n=\frac{\sum V n}{V t}
$$


Table 4:- Formula interpretation.

\begin{tabular}{|c|c|}
\hline \multicolumn{2}{|c|}{ to: } \\
\hline IGHS $_{\mathbf{m}}$ & Global index fulfilment hygienic prerequisites to HACCP System implementation in the study object. \\
\hline Ipn & Partial indicator index \\
\hline Wn & Indicator weight \\
\hline Vn & Value obtained by the criteria's \\
\hline Vt & Total points could attain the criteria \\
\hline
\end{tabular}

The scale selected for the IGHSm classification was taken in approach to (García \& Cepero, 2014).

Table 5:- Clasiffication of IGHSm according to the scale selected.

\begin{tabular}{|l|l|l|}
\hline IGHSm $\geq \mathbf{8 0}$ & OK & $\begin{array}{l}\text { haccp system CAN BE IMPLEMENTED and SANITARY license can be } \\
\text { GRANTED }\end{array}$ \\
\hline $\mathbf{8 0}>$ IGHSm $\geq \mathbf{5 0}$ & Regular & $\begin{array}{l}\text { The entity shows deficiencies. The administration should take actions to improve } \\
\text { the situation. The IGHSm must be applying in a period less than a month. }\end{array}$ \\
\hline IGHSm $<\mathbf{5 0}$ & LOW & $\begin{array}{r}\checkmark \text { HACCP system can't be implemented. } \\
\checkmark \text { Sanitary license most be withdrawn. }\end{array}$ \\
\hline
\end{tabular}

An IGHSm automatized application was developed where the user can access to the indicators to evaluate it. The application also generates a Report page where it gives the appearance of the detected problems and a graphic with the indicators behaviour. In addition the Report page shows up the incidence of every indicator in the obtained IGHSm. At this way, it's easily for the restaurant administration take measures to improve the detected situation.

Figure 3:- Main results page of the automatized IGHSm.

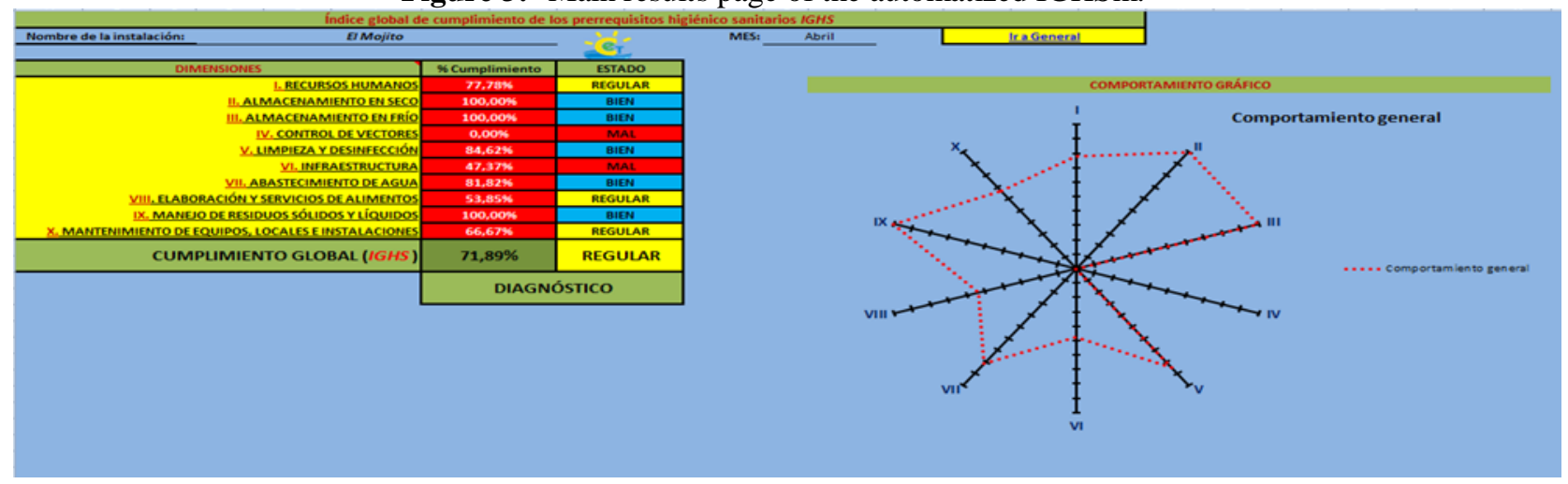

Figure 4:- Report page

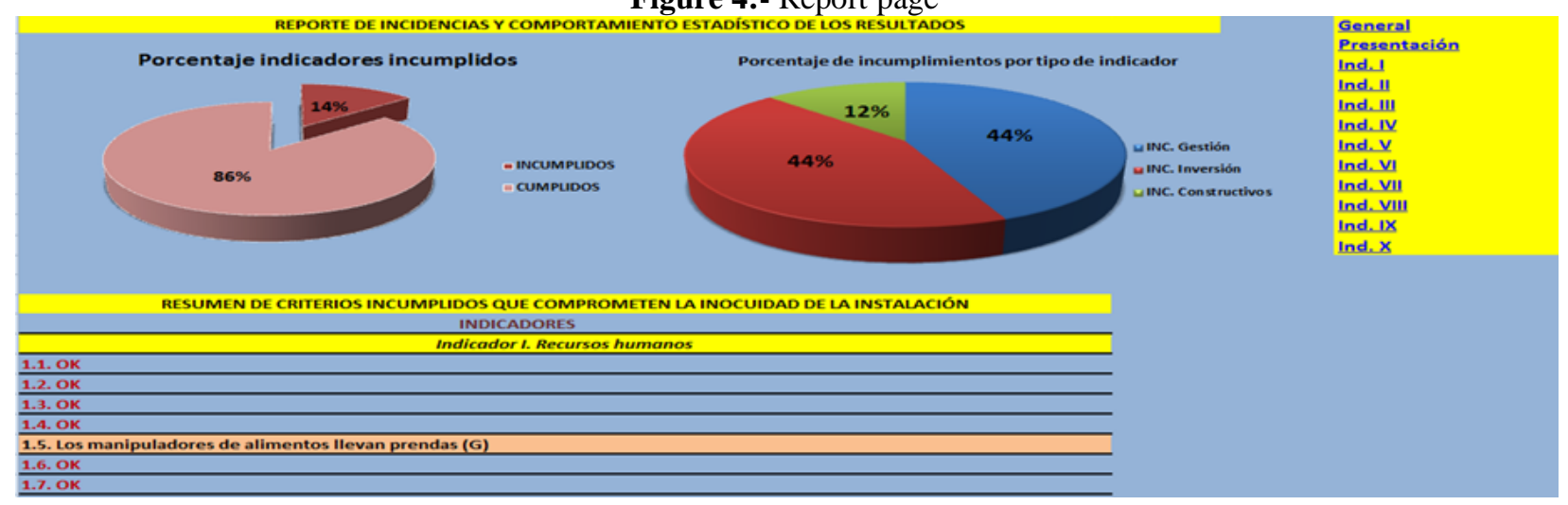




\section{Results and Discussions:-}

The application of the IGHSm came true in a specialized restaurant on the tourist destination of Varadero's. The evaluation evidenced a successfully fulfilment of 5 indicators with Ok evaluation. The others indicators were evaluated 3 (Regular) and 2 (Low), as a result did not let that the expected value be enough itself. The final Global index value was $70.14 \%$, for a Regular evaluation of the fulfilment prerequisites in the restaurant.

Table 6:- Indicators'́ fulfilment percentage

\begin{tabular}{|c|c|c|}
\hline INDICATORS & $\mathbf{\%}$ fulfillment & evaluation \\
\hline I. HUMAN RESOURCES & $70.00 \%$ & REGULAR \\
\hline II. DRY STORAGE & $90.00 \%$ & OK \\
\hline III. COLD STORAGE & $100.00 \%$ & OK \\
\hline IV. VECTORS CONTROL & $0.00 \%$ & LOW \\
\hline VI. INFRASTRUCTURE & $84.62 \%$ & OK \\
\hline VII. WATER SUPPLY & $45.00 \%$ & LOW \\
\hline V. CLEANLINESS AND DISINFECTATION & $81.82 \%$ & OK \\
\hline VIII. FOOD'S SERVICE AND ELABORATION & $53.85 \%$ & REGULAR \\
\hline IX. SOLIDS AND LIQUIDS WASTES MANAGEMENT & $100.00 \%$ & OK \\
\hline
\end{tabular}

Figure 5:- Graphical indicator's behavior.

\section{General indicators behavior}
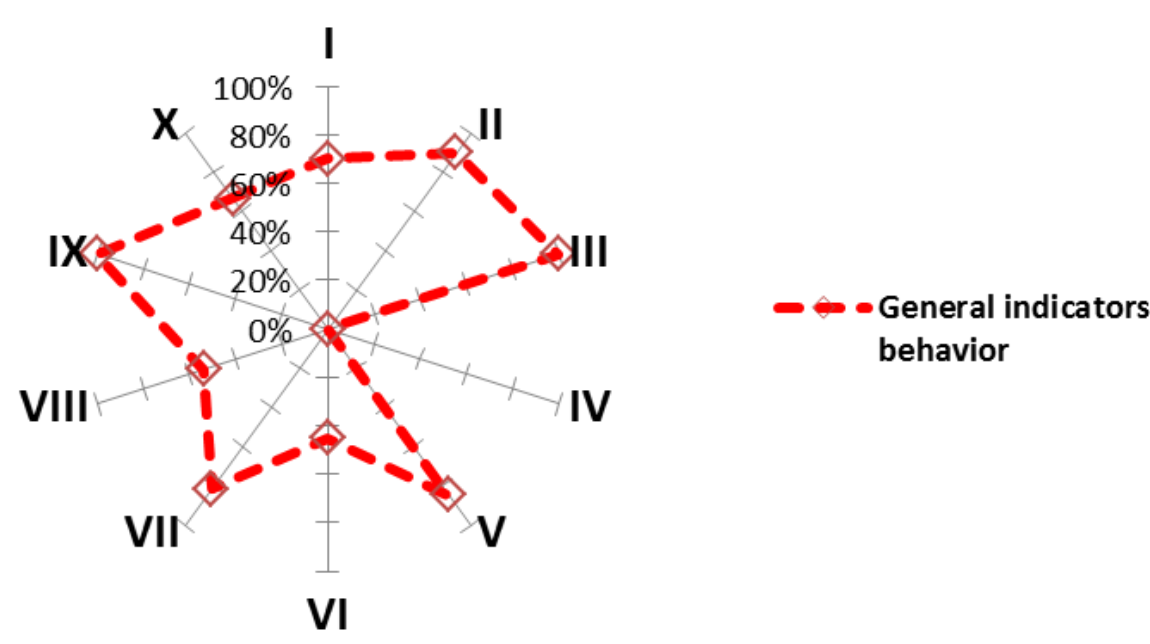
behavior

As can be see it the restaurant most pay special attention to indicators I, IV, VI, VIII and X. Because that are the ones that did not obtain reputable grade and compromise the food safety in the entity.

The indicators that obtained smaller percentage courtesy were IV and VI, falling short in the middle of its criteria the first one and the second one in 5 of them. These have a raised repercussion in the IGHSm, then they were evaluated LOW. It is important to take actions to avoid foodborne diseases and to maintain an entity's correct hygienic state. On the other hand indicators I, VIII and X obtained grade of REGULAR, all with a fulfilment over $65 \%$, which is why they do not have influence in kind than the above-mentioned in the IGHSm, with little corrections principally in the attitude of the staff these can get better in a short period of time.

The deficiencies detected in the application of the IGHSm, enabled the formulation of improvement actions in order to guarantee food innocuousness. Considering that the broadcast diagnosis was REGULAR with a punctuation obtained of $70.14 \%$, it is proposed that measures come true shortly. 
Table 7:- Corrective actions proposal.

\begin{tabular}{|c|c|c|}
\hline Actions & Place & Responsible \\
\hline $\begin{array}{l}\text { Placing sheet brasses of } 30 \mathrm{CM} \text { of stop to the front doors to avoid } \\
\text { vectors penetration. }\end{array}$ & Maintenance & $\begin{array}{l}\begin{array}{c}\text { Assistance Maintenance } \\
\text { director }\end{array} \\
\end{array}$ \\
\hline $\begin{array}{l}\text { Design a blueprint where expose themselves the positions of the } \\
\text { permanent round of beefs for rodents. }\end{array}$ & $\begin{array}{l}\text { Outside } \\
\text { areas }\end{array}$ & Manager \\
\hline $\begin{array}{l}\text { Placing the wire nettings to avoid the step from plagues to the } \\
\text { installation }\end{array}$ & Maintenance & $\begin{array}{l}\text { Assistance Maintenance } \\
\text { director }\end{array}$ \\
\hline $\begin{array}{l}\text { Exchanging the doors for some that have smooth surface and no- } \\
\text { absorbing properties. }\end{array}$ & Maintenance & $\begin{array}{l}\text { Assistance Maintenance } \\
\text { director }\end{array}$ \\
\hline $\begin{array}{l}\text { Replace the employees' bathroom service to the lateral left-hand } \\
\text { area of the restaurant to make a better use of the space and to } \\
\text { avoid the crossed contamination. }\end{array}$ & Maintenance & $\begin{array}{l}\text { Maintenance director and } \\
\text { Manager }\end{array}$ \\
\hline Placing steel plates rustles to the roofs and elevated equipment's & Maintenance & $\begin{array}{l}\begin{array}{c}\text { Assistance Maintenance } \\
\text { director }\end{array} \\
\end{array}$ \\
\hline $\begin{array}{c}\text { Accomplishing a good cleanliness during and after the work } \\
\text { period }\end{array}$ & Kitchen & Chef \\
\hline $\begin{array}{l}\text { Create the conditions for the correct defrosting of meats. } \\
\text { Acquire the necessary raw materials for the storage of the } \\
\text { products in containers made suitable, approved by Public } \\
\text { Health. Demanding the correct manipulation of the foods from } \\
\text { the kitchen staff afoot. }\end{array}$ & Kitchen & $\begin{array}{l}\text { Chef and Human } \\
\text { resource director }\end{array}$ \\
\hline Preserving the lamps from the site & Maintenance & $\begin{array}{l}\text { Assistance Maintenance } \\
\text { director }\end{array}$ \\
\hline Changing the damaged stone slabs & Maintenance & $\begin{array}{c}\text { Assistance Maintenance } \\
\text { director }\end{array}$ \\
\hline $\begin{array}{c}\text { Demand the not utilization of garments in the working space, } \\
\text { during preparation and service of the dishes }\end{array}$ & $\begin{array}{l}\text { Kitchen and } \\
\text { Saloon }\end{array}$ & $\begin{array}{l}\text { Chef, Maitre and } \\
\text { service's director }\end{array}$ \\
\hline
\end{tabular}

Table 8:- Check List ${ }^{1}$

\begin{tabular}{|c|c|}
\hline \multicolumn{2}{|l|}{ Indicator I. Human resources } \\
\hline Measures criteria & Yes/No \\
\hline \multicolumn{2}{|c|}{ M 1.2. All the workers that meet interacting with the foods do medical checkups come true periodically? } \\
\hline \multicolumn{2}{|c|}{ M 1.4. Do the manipulators hold a correct hygiene of the fingernails? } \\
\hline \multicolumn{2}{|c|}{ M 1.5. Do the manipulators fulfil the measures arranged for the personal hygiene, not using of garments? } \\
\hline \multicolumn{2}{|c|}{ M 1.8. Are the uniforms used adequately? } \\
\hline \multicolumn{2}{|c|}{ M 1.9. Do they demonstrate attitudes and hygienic adequate habits? } \\
\hline \multicolumn{2}{|l|}{ Indicator II. Dry storage } \\
\hline Measures criteria & Yes/No \\
\hline \multicolumn{2}{|c|}{ M 2.1. All the products do find on platforms at the very least to $15 \mathrm{CM}$ of the ground? } \\
\hline M 2.6. Does he show perfect state of organization? & \\
\hline
\end{tabular}

\footnotetext{
${ }^{1}$ The marked criteria (*) do not have value, because they become of obligatory fulfilment. If these criteria do not fail to keep themselves, becomes null the IGHSm and the evaluation does not proceed. In this cases the HACCP system can't be applied.

${ }^{2}$ First letter identified the criteria type: M (management); C (constructive); I (investment).
} 


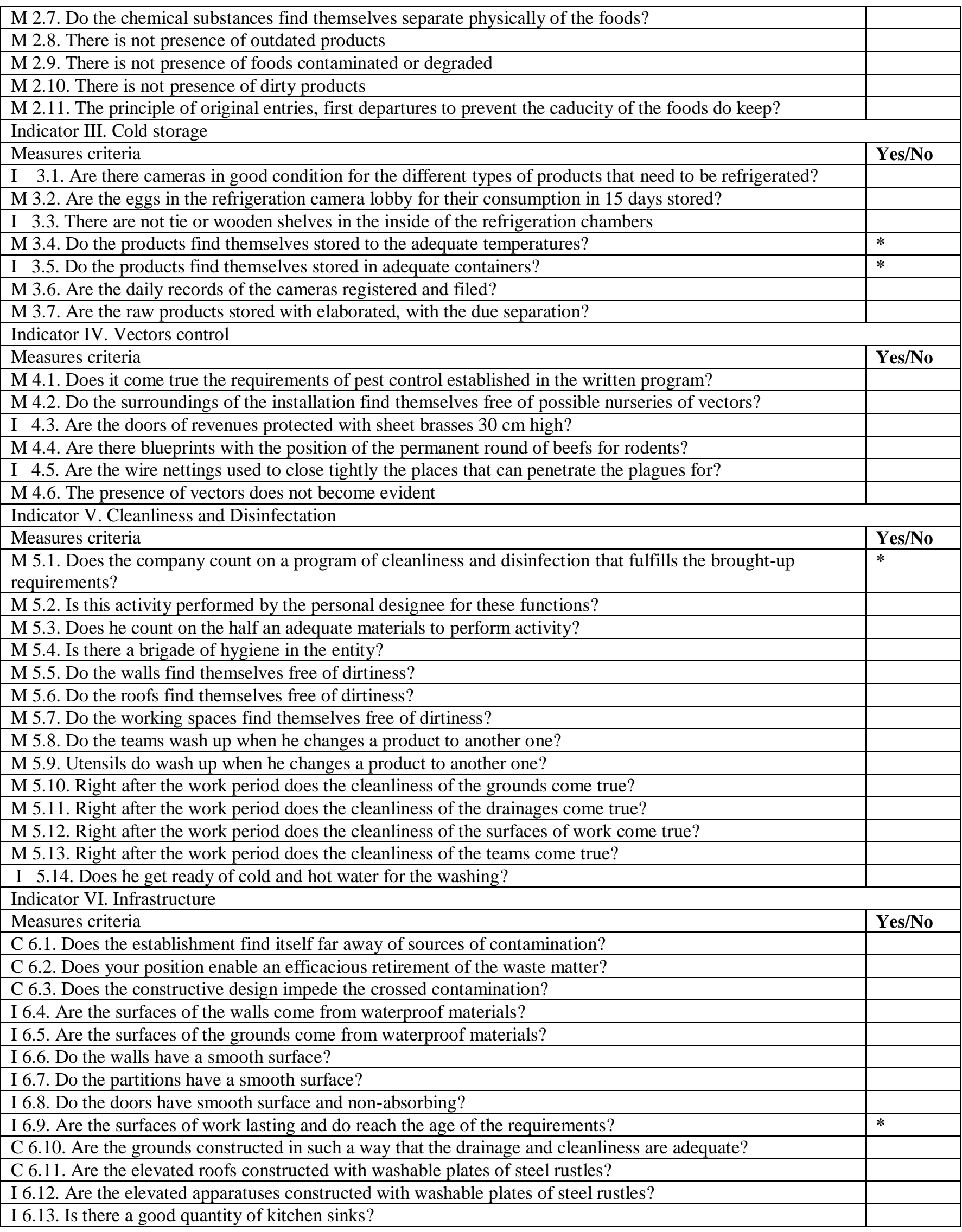




\begin{tabular}{|c|c|}
\hline 6.14. Do the kitchen sinks present a good hygienic shape during and after the work period? & \\
\hline M 6.15. Are the kitchen sinks gifted of means for the hygienization of the hands? & \\
\hline I 6.16. Is there a good quantity of washbasin in the areas of foods elaboration? & \\
\hline M 6.17. Are the washbasins gifted of means for the hygienization of the hands? & \\
\hline M 6.18. Do the washbasins show an adequate hygienic state? & \\
\hline I 6.19. Is there a good quantity of drains in the areas of elaboration? & \\
\hline M 6.20. Do the drains present good hygienic shape during and after the work period? & \\
\hline Indicator VII. Water supply & \\
\hline Measures criteria & Yes/No \\
\hline M 7.1. Does it come true with the existing program of water treatment? & \\
\hline I 7.2. Does the installation have an at the very least 24 -hour water supply? & \\
\hline $\begin{array}{l}\text { M 7.3. Does the records of drinking water chlorine level wash out two times a day, which must be between 0.3- } \\
1 \mathrm{mg} / 1 \text { ? }\end{array}$ & $*$ \\
\hline I 7.4. Are the cisterns protected of any contamination? & \\
\hline I 7.5. Are the tanks protected of any contamination? & \\
\hline I 7.6. Is the system (doesn't he include cisterns and tanks) protected of any contamination? & \\
\hline M 7.7. Is the water of consumption of the customers put into bottles? & \\
\hline M 7.8. Does ice manufacture with drinking water? & \\
\hline M 7.9. Is the extraction trowel of ice submerged in a breakup of chlorine after its use? & \\
\hline M 7.10. Is ice stored adequately to avoid his contamination? & \\
\hline M 7.11. The ice of does manipulate adequately to avoid its contamination? & \\
\hline I 7.12 Is Not presence of leaks in pipes & \\
\hline Indicator VIII. Food's service and elaboration & \\
\hline Measures criteria & Yes/No \\
\hline M 8.1. Fruits do graduate clean in containers made suitable of units of production approved by Public Health? & * \\
\hline $\begin{array}{l}\text { M 8.2. Vegetables do graduate clean in containers made suitable of units of production approved by Public } \\
\text { Health? }\end{array}$ & * \\
\hline M 8.3. Does the manipulation of the eggs come true according to the sanitary requirements for this activity? & * \\
\hline M 8.4. The semi-raw products do become elaborate from certified free meats of pathogens? & \\
\hline M 8.5. Are they taken and do the samples keep control correctly? & \\
\hline I 8.6. Do the foods on exhibition find themselves protected with crystals or containers? & \\
\hline $\begin{array}{l}\text { M 8.7. Does he walk away with foods record of the temperatures of the tables of exposition, being verified that } \\
\text { they are them adequate and that the foods of risk not find themselves at room temperature? }\end{array}$ & \\
\hline M 8.8. Are there specific areas for the preparation of the different groups of products? & \\
\hline M 8.9. Does the defrosting of meats come true slowly in refrigeration? & \\
\hline M 8.10. Does it thaw only the products in the portions to be used? & \\
\hline M 8.11. Do the foods under preparation keep themselves in containers well covered and are they cool? & \\
\hline M 8.12. Does it come true with the beginning of parade forward? & * \\
\hline I 8.13. The teams destined to fulfil the requirements to the manipulation of foods? & \\
\hline I 8.14. Do the utensils destined to the manipulation of foods fulfil the requirements? & \\
\hline M 8.15. They do not reuse the disposable tableware's & \\
\hline M 8.16. Do the teams wash up when he changes a product to another one? & \\
\hline M 8.17. Utensils do wash up when he changes a product to another one? & \\
\hline Indicator IX. Solids and liquids wastes management & \\
\hline Measures criteria & Yes/No \\
\hline M 9.1. Does the program of solid wastes and liquids come true with all his required specifications? & \\
\hline $\begin{array}{l}\text { I 9.2. Are the solid wastes gathered in located independent plastic bags in metallic or plastic deposits of } \\
\text { adequate capacity? }\end{array}$ & \\
\hline M 9.3. Do the deposits keep themselves in places that do not offer risk of contamination? & * \\
\hline I 9.4. Does he get ready of facilities for the storage of the waste matter before your elimination of the entity? & \\
\hline I 9.5. An efficacious system of evacuation of effluents does have? & \\
\hline I 9.6. An efficacious system of evacuation of waste matter does have? & \\
\hline I 9.7. Are there traps of fat located out-of-doors and to leeward of the installation? & \\
\hline M 9.8. The containers destined to manipulation or conservation of foods are not us & \\
\hline
\end{tabular}




\begin{tabular}{|l|l|}
\hline wastes & \\
\hline Indicator X. Maintenance of equipment's, sites and facilities & Yes/No \\
\hline Measures criteria & \\
\hline $\begin{array}{l}\text { M 10.1. Does it come true with what's established in the program of maintenance with the pertinent } \\
\text { characteristics? }\end{array}$ & \\
\hline I 10.2. Do the kitchen sinks reach the age of the requirements to guarantee a correct hygienization? & \\
\hline I 10.3. There is no evidence of leak or dripping of the water pipes or residual & \\
\hline I 10.4. Does elaboration areas haves the pertinent illumination? & \\
\hline I 10.5. Do they have lamps protected in case of breaking in the different elaboration areas? & \\
\hline $\begin{array}{l}\text { I 10.6. Does the dishwasher's machines attain pressure and adequate temperature to guarantee cleanliness and } \\
\text { disinfection of the tableware? }\end{array}$ & \\
\hline I 10.7. There are not chippings in floors & \\
\hline I 10.8. There are not chippings in walls & \\
\hline I 10.9. There are not damaged floors slabs & \\
\hline I 10.10. There are not grids damages & \\
\hline I 10.11. Do the walls find themselves free of humidity and stains? & \\
\hline I 10.12. Do the roofs find themselves free of humidity and stains? & \\
\hline
\end{tabular}

\section{Conclusions:-}

The diagnosis hygienic prerequisites fulfilment it's an important and necessary step in HACCP system implementation. The proposed instrument allows quantify the behaviour of hygienic prerequisites and the determination of Global fulfilment index (IGHSm) for the diagnosis of the same in gastronomic services, establishing oneself a minimal value of performance. The proposal also include a manual drives complementary and an automated application of the IGHSm. The practical instrument validation in a restaurant of Varadero's tourist destination resulted in a $70.14 \%$, value of IGHSm fulfilment, making the proposal of improvement actions of shortterm possible in like manner. The indicators which obtained smaller percentage courtesy were IV (Vector control) and VI (Infrastructure), falling short in the middle of its criteria's, with a significant negative repercussion in the final IGHSm value. The application of the proposed instrument allows identifying 11 improvement actions to the innocuousness management in the restaurant.

\section{References:-}

1. Armendáriz, C.; Monge, Y. \& Zhunio, B. (2012): «Analysis of the three more common diseases produced by the bad manipulation of foods in the sector of Cotocollao». RICIT, 4: 45-57.

2. Avila, A. (2011): «Restaurant management». Presented thesis in option to Master's in Tourism Management. 382p. Matanzas University "Camilo Cienfuegos". Matanzas, Cuba.

3. Barrio Sugita (2009), taken from GUADA, Y. (2011): «Procedure for the self-control of the innocuousness of the foods in the process of restoration of the Cienfuegos Club». Thesis in option to Master's in Tourism Management. Faculty of Economics and Information Technology. Matanzas University "Camilo Cienfuegos". Cuba.

4. Carballo, A. R, Villarreal, A. \& Del Toro, J. J. (2012): «The nutritional label, politics of food security». Journal Research and Development. 20(1): 168-189. ISSN: 2011-7574.

5. Celaya, C. (2004): «Evaluation of HACCP system implantation in the small food industries of the community of Madrid». Thesis in option to Master's in Nutrition, Bromatology and Food's technology. Nutrition's, Bromatology's and Technology's Food Department. Veterinary Faculty ED. Complutense University of Madrid. Spain. ISBN: 84-669-2849-9.

6. Cepero, S. \& García, Y. A. (2014): «Diagnosis of the fulfilment hygienic prerequisites in the restaurant Varadero's 1887 of the hotel Playa de Oro». Thesis in option to degree in Tourism. Tourism Department. Faculty of Economics and Information Technology. Matanzas University "Camilo Cienfuegos".

7. Correia Paulino, E.; Gomoes, H. \& Franc, T. (2012): «High-quality step of the service of foods and drinks». Education and perspectives in tourism volume 21 pages. 763-777.

8. Espinosa, J. M. Bilbao Reboredo, J, Marrero Moral, M., Méndez Rodríguez Arencibia, J. L. \& González Peláez, F. F. (2010): «The hygiene in the restoration». Restoration management. Editorial, Felix Varela. ISBN: 978-959-07-1282-1. 179-202. 
9. Frías, R. A.; Cuétara, L.; González, M.; González, A. \& Corzo, Y. (2008) «Backup tools to the solution of problems not structured in tourist companies». Editorial University, Matanzas University "Camilo Cienfuegos". ISBN: 959-16-0304-9.

10. García, Y. A. (2014): «Earnings Report of the impact tasks of the 1st year of the Bachelor's Degree in Tourism at Matanzas University». Tourism Department. Faculty of Economics and Information Technology.

11. López, S. Del C, \& Osorio, N. (2012): «Design of a system of management of the food safety for a readycooked- rice processing plant». Thesis in option to Engineering's title in Foods Science. School of chemical engineering and food engineering. Faculty of Engineering and Architecture. The Savior's University.

12. Macías, J. M. (2013): «Procedure for the improvement of the innocuousness management of foods in the kitchen of Pasacaballos hotel». Thesis in option to Master's scientific degree in Tourism Management. Faculty of Economics and Information Technology. Matanzas University "Camilo Cienfuegos".

13. Moya, N \& Zubieta, K. (2013): «Evaluation of the system of management of the quality in the innocuousness of foods and drinks of the hotel Tamanaco Intercontinental Caracas». Thesis presented in option to the title of tourist companies Administration. Tourist school of business administration. Faculty of management sciences. New University Sparta. Republic Bolivarian of Venezuela.

14. NC 136:2017. «Hazard Analysis and Critical Control Points (HACCP System), directions for its implementation». Third edition, Cuba.

15. NC 143:2007. «Food safety-general principles Code». First edition, Cuba.

16. NC 453:2006. «Collective nutrition-general hygienic requirements». Obligatory character. First edition, Cuba.

17. NC 455:2006. «Food handling, general hygienic requirements». Second edition, Cuba.

18. Suárez Castro, H. (2012): «Implementation of the HACCP System in the restaurant Don Pascuale of the Sandals Royal Hicacos Resorts SPA hotel». Thesis in option to degree in Tourism. Tourism Department. Matanzas University. Matanzas, Cuba.

19. Suárez, Y.; Suasnavas, N.; Calzadilla, C.; Cepero, O. \& Castillo, J. C. (2007): «Evaluative procedures of some prerequisites for the application of the HACCP system in slaughterhouses». REDVET. Veterinarian's E-zine. ISSN: 1695-7504. VIII(8): 1-11. Spain. Available in: http://www.redalyc.org/articulo.oa?Id63612734007 [Consulted January, 2014].

20. Todt, O. (2008): «Between social request and regulation: The food security». Latin American Science's, Technology and Society journal - CTS, January, REDES. Seat of learning on Science, Development and Higher Education. Argentina, 4(10): 183-195. ISSN 1650-0013.

21. Tourist Bulletin 5130. (2014): Gastronomic tourism and food security. Available in: www.boletinturistico.com... /k2... /5130 tourism and certainty alimentary [consulted]: January 2015.

22. Villalobos Sánchez, Gómez Rodríguez \& Delgado Álvarez. (2010): The HACCP System. Barriers and actions for its implementation from a perspective. CTS, gratuitous Electronic Publishing. Complete text in: www.eumed.net/libros/2010d/793/. 